Article

\title{
Endowing Acceptable Mechanical Properties of Segregated Conductive Polymer Composites with Enhanced Filler-Matrix Interfacial Interactions by Incorporating High Specific Surface Area Nanosized Carbon Black
}

\author{
Huibin Cheng ${ }^{1} \Subset$, Xiaoli Sun ${ }^{1}$, Baoquan Huang ${ }^{1}$, Liren Xiao ${ }^{2}$, Qinghua Chen ${ }^{1,2,3}$, Changlin Cao ${ }^{1, *}$ and \\ Qingrong Qian 1,2,3,*iD \\ 1 College of Environmental Science and Engineering, Fujian Normal University, Fuzhou 350007, China; \\ QBX20190099@yjs.fjnu.edu.cn (H.C.); sunxiaoli@fjnu.edu.cn (X.S.); qbh811@fjnu.edu.cn (B.H.); \\ cqhuar@fjnu.edu.cn (Q.C.) \\ 2 Engineering Research Center of Polymer Green Recycling of Ministry of Education, Fuzhou 350007, China; \\ xlr1966@fjnu.edu.cn \\ 3 Fujian Key Laboratory of Pollution Control \& Resource Reuse, Fuzhou 350007, China \\ * Correspondence: caochlin3@fjnu.edu.cn (C.C.); qrqian@fjnu.edu.cn (Q.Q.)
}

Citation: Cheng, H.; Sun, X.; Huang, B.; Xiao, L.; Chen, Q.; Cao, C.; Qian, Q. Endowing Acceptable Mechanical Properties of Segregated Conductive Polymer Composites with Enhanced Filler-Matrix Interfacial Interactions by Incorporating High Specific Surface Area Nanosized Carbon Black. Nanomaterials 2021, 11, 2074. https://doi.org/10.3390/nano11082074

Academic Editors: Mohammad Malikan and Ana María Díez-Pascual

Received: 16 July 2021

Accepted: 11 August 2021

Published: 16 August 2021

Publisher's Note: MDPI stays neutral with regard to jurisdictional claims in published maps and institutional affiliations.

Copyright: (C) 2021 by the authors. Licensee MDPI, Basel, Switzerland. This article is an open access article distributed under the terms and conditions of the Creative Commons Attribution (CC BY) license (https:/ / creativecommons.org/licenses/by/ $4.0 /)$.

\begin{abstract}
Tuning the high properties of segregated conductive polymer materials (CPCs) by incorporating nanoscale carbon fillers has drawn increasing attention in the industry and academy fields, although weak interfacial interaction of matrix-filler is a daunting challenge for high-loading CPCs. Herein, we present a facile and efficient strategy for preparing the segregated conducting ultra-high molecular weight polyethylene (UHMWPE)-based composites with acceptable mechanical properties. The interfacial interactions, mechanical properties, electrical properties and electromagnetic interference (EMI) shielding effectiveness (SE) of the UHMWPE/conducting carbon black (CCB) composites were investigated. The morphological and Raman mapping results showed that UHMWPE/high specific surface area CCB (h-CCB) composites demonstrate an obviously interfacial transition layer and strongly interfacial adhesion, as compared to UHMWPE/low specific surface area CCB (1-CCB) composites. Consequently, the high-loading UHMWPE/h-CCB composite (beyond $10 \mathrm{wt} \%$ CCB dosage) exhibits higher strength and elongation at break than the UHMWPE/1-CCB composite. Moreover, due to the formation of a densely stacked h-CCB network under the enhanced filler-matrix interfacial interactions, UHMWPE/h-CCB composite possesses a higher EMI SE than those of UHMWPE/1-CCB composites. The electrical conductivity and EMI SE value of the UHMWPE/h-CCB composite increase sharply with the increasing content of h-CCB. The EMI SE of UHMWPE/h-CCB composite with $10 \mathrm{wt} \% \mathrm{~h}-\mathrm{CCB}$ is $22.3 \mathrm{~dB}$ at X-band, as four times that of the UHMWPE/1-CCB composite with same l-CCB dosage (5.6 dB). This work will help to manufacture a low-cost and high-performance EMI shielding material for modern electronic systems.
\end{abstract}

Keywords: interfacial interaction; conducting carbon black network; mechanical property; electromagnetic interference shielding

\section{Introduction}

With the rapid advancement in electronic information technology, electronic equipment and communication base stations have become an indispensable part of people's daily lives. Meanwhile, this originated from man-made electronic devices accompanied by high-energy electromagnetic wave radiation pollution and electromagnetic interference have become critical problems that need to be addressed [1,2]. Current electromagnetic interference (EMI) shielding materials mainly include metal and their alloy materials, but these materials have many shortcomings, such as high density, high cost, low corrosions and a complicated manufacturing process [3]. Therefore, the electrically conductive 
polymer composites (CPCs) containing conductive fillers were identified as one of the excellent candidates for EMI shielding materials due to their excellent merits, such as low density, regulable electrical conductivity and corrosion resistance, etc. [4-7]. To effectively reduce the impact of electromagnetic wave radiation on interfering with the equipment and human health, especially, people paid widespread attention to the design and fabrication of lightweight and highly electrical conducting carbon fillers filled CPCs. In recent years, to obtain higher EMI shielding effectiveness (SE) value, CPCs must require sufficient conductive loss and interface polarized loss. Additionally, a reasonable layout of the conductive network is necessary [8-10]. The construction of stable, efficient and integral conductive paths can be helpful for conductive loss. Unfortunately, highly efficient conductive pathways always require high content filler loading, which inevitably affects the mechanical properties and processibility of materials [11,12]. Thus, how to further obtain an efficient and dense conductive network at low content loading for EMI shielding polymer composites still remains a daunting challenge [13].

The segregated conductive pathway has proven to outperform in enlarging conductive loss mechanism, particularly for lightweight polymer-based EMI shielding materials with segregated structure, multi-element composite structure, laminated structure and multi-interface structure [13-17]. Unfortunately, the segregated conductive pathways may cause low enhancement efficiency of mechanical properties. The choice of the polymer matrices and electrically conductive fillers, and the interface microstructure of polymerfiller are very important for solving undesirable mechanical properties and manufacturing high-performance CPCs. Currently, tremendous efforts in overcoming the disperse and weak interfacial interaction of nanocarbon filler, such as carbon nanotube (CNT) [18-22], graphite (G) [23], carbon black [21,24] and graphene nanoplatelets (GNPs) $[25,26]$, etc. Numerous works have attempted to improve the interface interaction of CPCs by the synergistic effect of different dimensional filler and surface modification of filler [27,28]. $\mathrm{Li}$ [23] et al. reported hybrid graphite/carbon black (CB)/ultrahigh molecular weight polyethylene (UHMWPE) composite exhibited a high electrical conductivity and superb EMI SE. The mechanical enhancement is attributed to the synergistic effect of the nanosized CB particles and large-aspect-ratio graphite platelets, providing a stronger interfacial adhesion between UHMWPE domains. Nah, et al. [29] developed a highly scalable EMI shielding material comprising nanostructured carbon black and poly (methyl methacrylate) (PMMA) nanocomposites via solution mixing, followed by the compression molding method. The obtained PMMA nanocomposite with $10 \mathrm{wt} \%$ filler loading possessed a superior EMI SE value of $\sim 28 \mathrm{~dB}$ at $\mathrm{X}$ band. Moreover, inspired by the microstructure of the bio-structural materials [30-32], people learn from nacre to construct unique structural polymer composites-that is, design the orderly morphology of multi-layered structural polymer matrix and the alignment of inorganic fillers. The thermal conductivity, electrical properties and mechanical properties of polymer/filler nanocomposites were improved via interface engineering [33,34]. However, among these methods in enhancing the fillermatrix, interfacial interactions is relatively complicated for the practical production process. Thus, for CPCs with strong interface adhesion and small defects, whether they can simply employ low-cost and high-electrically conductive nanostructured carbon fillers for developing EMI shielding materials has become a very perspective research hotspot $[35,36]$.

In this work, UHMWPE with unique rheological property serves as a matrix of segregated conductive polymer composites, and nanosized carbon black (CCB) with high and low specific surface area acts as conductive fillers. A comparative study of CPCs with a dense high specific surface area conductive carbon black (h-CCB) packing network and a low specific surface area conductive carbon black (l-CCB) loose network based on an UHMWPE matrix was fabricated through mechanical mixing and compression molding methods. We found that h-CCB particles with the multi-nanopores and intensive polar interaction can not only be used as a conducting agent to enhance the electrical conductivity of UHMWPE, but also as transition layer to improve the filler-matrix interfacial interactions, which in turn effectively suppress interfacial defects between the adjacent 
UHMWPE and h-CCB domains, and greatly form a highly efficient dense conductive network in the composite. The achieved high-loading UHMWPE-based CPCs exhibited a significant improvement of EMI shielding performance and mechanical properties. Furthermore, to meet the requirement of actual applications, the influence of h-CCB and l-CCB content on phase morphology, interfacial bonding mechanism, thermal properties and EMI SE of high loading UHMWPE/CCB composites beyond $10 \mathrm{wt} \%$ CCB dosage were investigated comprehensively.

\section{Materials and Methods}

\subsection{Materials}

CCB (F900A) with a high specific surface area (h-CCB) of $380 \mathrm{~m}^{2} / \mathrm{g}$ were purchased from Tianjin Ebory Chemical Co., Ltd., (Tianjin, China). CCB (Orion N990) with a low specific surface area (l-CCB) of $8 \mathrm{~m}^{2} / \mathrm{g}$ was obtained from Shenzhen Securities Yoshida Chemical Co., Ltd., (Shenzhen, China). Comparison of the specific surface area and pore size distribution of two kinds of CCB nanoparticles were given in Figure S1 and Table S1. UHMWPE, under the trade of SLL-2, with an average molecular weight of $3.00 \times 10^{6} \mathrm{~g} / \mathrm{mol}$, was supplied by Shanghai Lianle Chemical Industry Science and Technology Co., Ltd., (Shanghai, China). All raw materials were used as received without further modification.

\subsection{Preparation of UHMWPE/CCB Composites}

The preparation schematic illustration of segregated UHMWPE/CCB composites is presented in Figure 1. At first, h-CCB particles and UHMWPE powder were dried in a vacuum oven at $80^{\circ} \mathrm{C}$ for $6 \mathrm{~h}$. Then, UHMWPE powder and high specific surface area h-CCB particles with compositions of 99.5/0.5, 99/1, 97/3, 95/5, 93/7, 90/10 and 85/15 were premixed by adopting the crusher high-speed mechanical mixing (800Y, Yongkang Platinum Ou Hardware Products Co., Ltd., Zhejiang, China) at a rotation speed of 34,000 r/min for $50 \mathrm{~s}$, obtaining the high specific surface area CCB-coated UHMWPE mixtures. Afterward, the obtained compounds were compression molded at $200{ }^{\circ} \mathrm{C}$ for $20 \mathrm{~min}$ on a flat vulcanizing machine (ZG-80 T, Guangdong Zhenggong Electromechanical Equipment Technology Co., Ltd., Guangdong, China), followed by cold compression molded to room temperature at a pressure of $17 \mathrm{MPa}$. The final obtained specimens were denoted as UHMWPE $/ \mathrm{h}-\mathrm{CCB}_{\mathrm{x}}$ composites, in which $x$ means that the weight fraction of h-CCB nanoparticles. For comparison, l-CCB nanoparticles modified UHMWPE composites with the same weight ratios were prepared via high-speed mechanical mixing and compression molding. The samples were remarked as UHMWPE/1-CCB $\mathrm{x}$ composites.

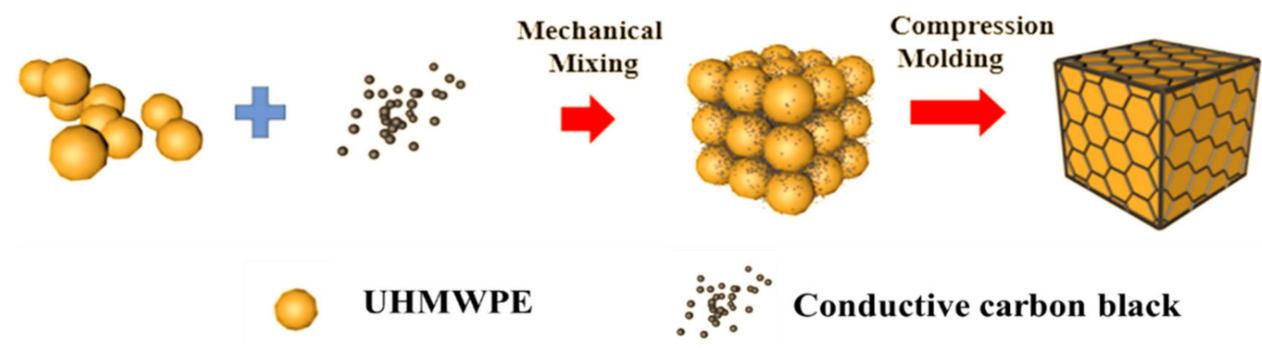

Figure 1. Preparation schematic illustration of segregated UHMWPE/CCB composites.

\subsection{Characterization}

The morphologies of CCB nanoparticles and composites were investigated using a cold field emission scanning electron microscope (FE-SEM, Regulus 8100, Hitachi, Japan) at an accelerating voltage of $10 \mathrm{kV}$. All samples were fractured in liquid nitrogen and sputter-coated with gold before observation.

The electrical conductivity was measured by a high-resistance meter (ZC-90G, Shanghai Taiou Electronics Co., Ltd., Shanghai, China) higher than $10^{-5} \mathrm{~S} / \mathrm{m}$, four-point probes resistivity measurement (RTS-9, Guangzhou Four Probe Technology Co., Ltd., Guangzhou, 
China) below $10^{-5} \mathrm{~S} / \mathrm{m}$. The electromagnetic interference shielding performance of the samples depended on scattering parameters, which corresponded to the reflection and transmission of transverse electromagnetic waves, was performed by a Vector network analysis (N5244A, Agilent Technologies, SCC, CA, USA) with the wave-guide method at X-band frequency range $(8.2-12.4 \mathrm{GHz})$ according to ASTM D5568-08, the resultant scattering parameters were used to calculate EMI SE values.

The sheets were cut into dumbbell-shaped specimens for the evaluation of the mechanical properties using a universal testing machine (CMT4104, Shenzhen Sans Material Inspection Co., Ltd., Shenzhen, China). The measurements were repeated five times to get the average values.

The DSC analyses for the samples were performed on a TA Instruments Q20. The samples were first heated up to $200^{\circ} \mathrm{C}$, and then annealed for $5 \mathrm{~min}$ to eliminate thermal history, following by cooling down to $40{ }^{\circ} \mathrm{C}$ and then reheated up to $200{ }^{\circ} \mathrm{C}$, at heating and cooling rates of $10^{\circ} \mathrm{C} / \mathrm{min}$. Thermal gravimetric (TGA) analysis of the samples was performed by TA instrument $\mathrm{Q} 50$ from room temperature to $700{ }^{\circ} \mathrm{C}$ at a heating rate of $10^{\circ} \mathrm{C} / \mathrm{min}$ and a nitrogen gas flow of $90 \mathrm{~mL} / \mathrm{min}$.

The specific surface area of CCB particles was tested using a BELSOBP-miniII automatic surface area Brunauer-Emmet-Teller (BET) analyzer (BELSOBP-miniII, MicrotracBEL, Osaka, Japan). The specific surface area was calculated according to the Brunauer-EmmettTeller (BET) method.

To order to indicate intuitively the interface interactions between UHMWPE and CCB particles with various structures, the Raman mapping images of UHMWPE/h-CCB and UHMWPE/1-CCB composites were performed on a micro-laser confocal Raman spectrometer (Thermo Scientific DXR2xi, Waltham, MA, USA). The test condition of Raman was that the laser power is $1.5 \mathrm{~mW}$, and the total exposure is 30 times with $0.025 \mathrm{~s}$ exposure time for each spectrum, Raman mapping images with an area of $50 \mu \mathrm{m}^{2}$ in step sizes of $1 \mathrm{~m}$. The imaging data is fitted through the Raman software "OMNICxi", which gives each point a corresponding Raman characteristic peak spectrum.

\section{Results}

\subsection{Characterization of $h-C C B$, and l-CCB Nanoparticles}

We investigated the microstructure and properties of two kinds of CCB nanoparticles. These particles are often agglomerated into large aggregates due to the strong Van der Waals force between particles, leading to a high-percolation threshold value (15-20 wt $\%)$ for achieving the interconnected conductive networks [37]. This is mainly due to the zero-dimensional shape of the filler, which is hard to construct highly efficient conductive networks [38]. Figure 2 depicts the morphology and specific surface area of two kinds of nanoscale h-CCB or 1-CCB particles. In Figure 2a,b, compared to 1-CCB materials, we observed that the particle size of h-CCB is smaller than l-CCB, and most of h-CCB particles aggregate each other, it shows that h-CCB possesses a high specific surface area and strong polar interaction between particles. Figure $2 \mathrm{c}$ presents the $\mathrm{N}_{2}$ adsorption/desorption isotherms of two kinds of different specific surface area CCB nanoparticles; it suggests that the large specific surface area of h-CCB particles was attributed to its abundant porous structure, and the abundant mesoporous structure and high specific surface area of h-CCB particles enable the combined forces of numerous Van der Waals forces to become much stronger, which is beneficial for forming the strong interface interactions of mechanical interlocking between h-CCB and UHMWPE. Figure $2 \mathrm{~d}$ indicates that Raman spectrum of h-CCB and l-CCB particles is mainly composed of D and G peaks at $1348 \mathrm{~cm}^{-1}$ and $1587 \mathrm{~cm}^{-1}$, in which $\mathrm{I}_{\mathrm{D}} / \mathrm{I}_{\mathrm{G}}$ value presented the level of the different graphitization and defects structure. Moreover, h-CCB particles present an evident $2 \mathrm{G}$ peak value in the Raman spectrum, the $\mathrm{I}_{\mathrm{D}} / \mathrm{I}_{\mathrm{G}}$ value of $\mathrm{h}-\mathrm{CCB}$ is lower than 1-CCB particles, implying the graphitization degree of h-CCB particles is higher than l-CCB particles. These results suggested that h-CCB particles with high graphitization level serve as conducting fillers 
in CPCs at low filler content, which has more competitive value in industry applications, owing to its outstanding electrical conductivity.
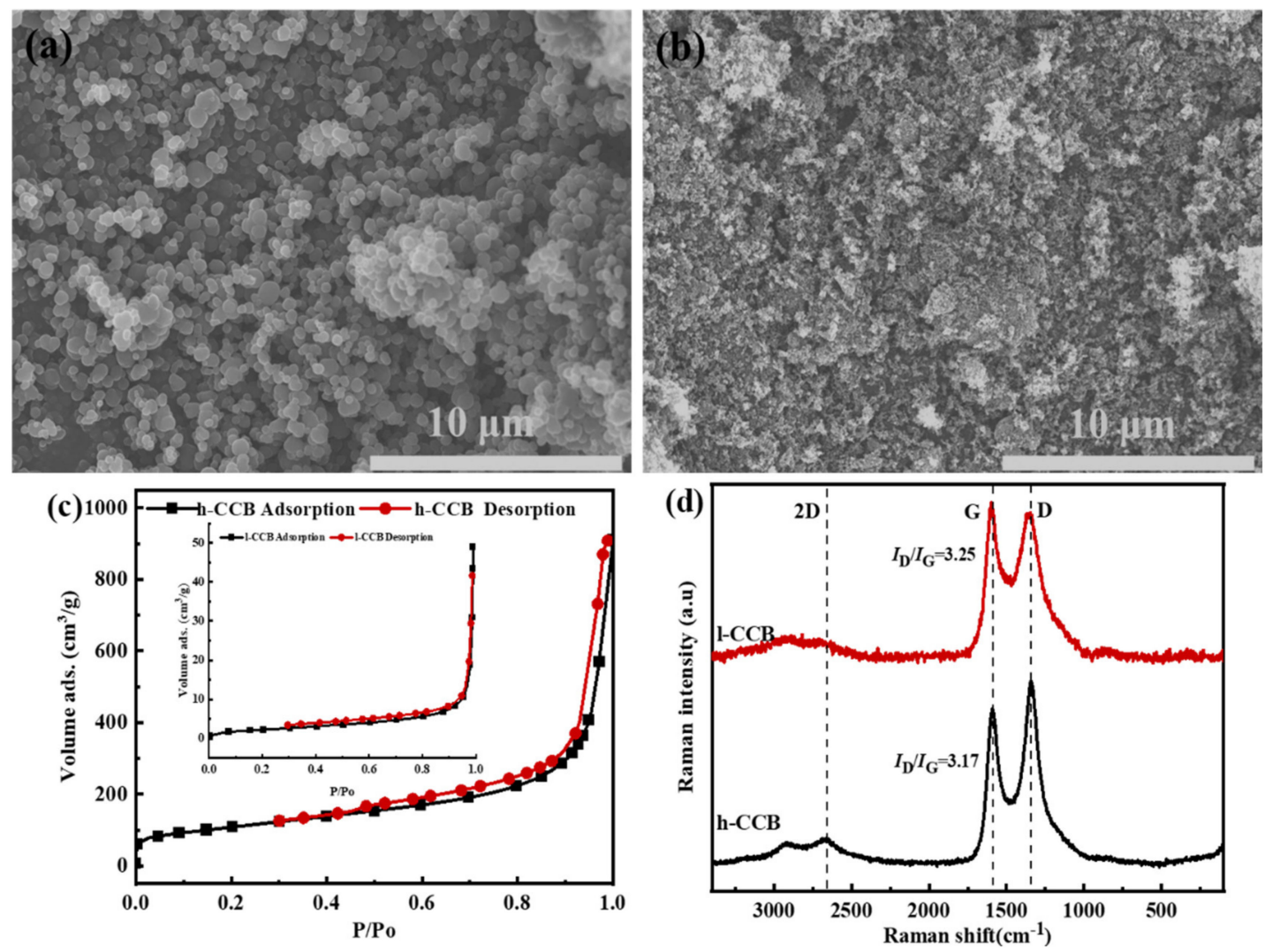

Figure 2. SEM images of CCB particles: (a) l-CCB particle; (b) h-CCB particles; (c) $\mathrm{N}_{2}$ adsorption/desorption isotherms, (d) Raman spectroscopy of nanoscale h-CCB and l-CCB particles.

\subsection{Microstructure of UHMWPE/CCB Composites}

To vitally confirm the various dispersion and distribution characteristics of $\mathrm{CCB}$ particles, we perform optical microscopy $(\mathrm{OM})$ imaging analysis. Figure 3 shows the cross-sectional optical microscopy of UHMWPE/l-CCB composites and UHMWPE/h-CCB composites. The obvious bright parts (UHMWPE region) and dark region (h-CCB or $1-C C B$ rich region) that are connected can be observed clearly, indicating the formation of a segregated h-CCB or 1-CCB network. In Figure 3a-c, with the increasing 1-CCB content, some conductive networks are gradually constructed. Likewise, this phenomenon also appears in h-CCB filled UHMWPE matrix, as shown in Figure 3e,f. Compared to the loosely stacked 1-CCB network, while the strong Van der Waals forces of h-CCB particle are easy to aggregate each other, and gradually form a denser and denser developed conductive network with increasing h-CCB concentrations. This may be attributed to the strong mechanical interlocked interactions of h-CCB particles and UHMWPE matrix, and the Brownian motion of CCB particles in the UHMWPE melt creates the distinctly interfacial transition layer and strongly interfacial adhesion, forming the densely stacked conductive network [35]. To sum up, the optical microscopy observations intuitively confirm the formation of high-quality segregated conductive networks. An interfacial transition layer with the small interface defect is achieved in UHMWPE/h-CCB composites due to the strong interfacial effects. Moreover, we observed that a compacted and oriented conductive pathway near the UHMWPE granules interfacial regions is formed at the optical microscopy of UHMWPE/h-CCB composites (Figure 3e). This result is likely due to the high viscosity of the UHMWPE matrix, which promotes the migration of h-CCB particles during the hot-compression process. With the increase of h-CCB particles dosage, 
the migration of h-CCB particles attached to the UHMWPE granules interfacial regions become dense and thick, which further reveals good interfacial adhesion between h-CCB and UHMWPE.

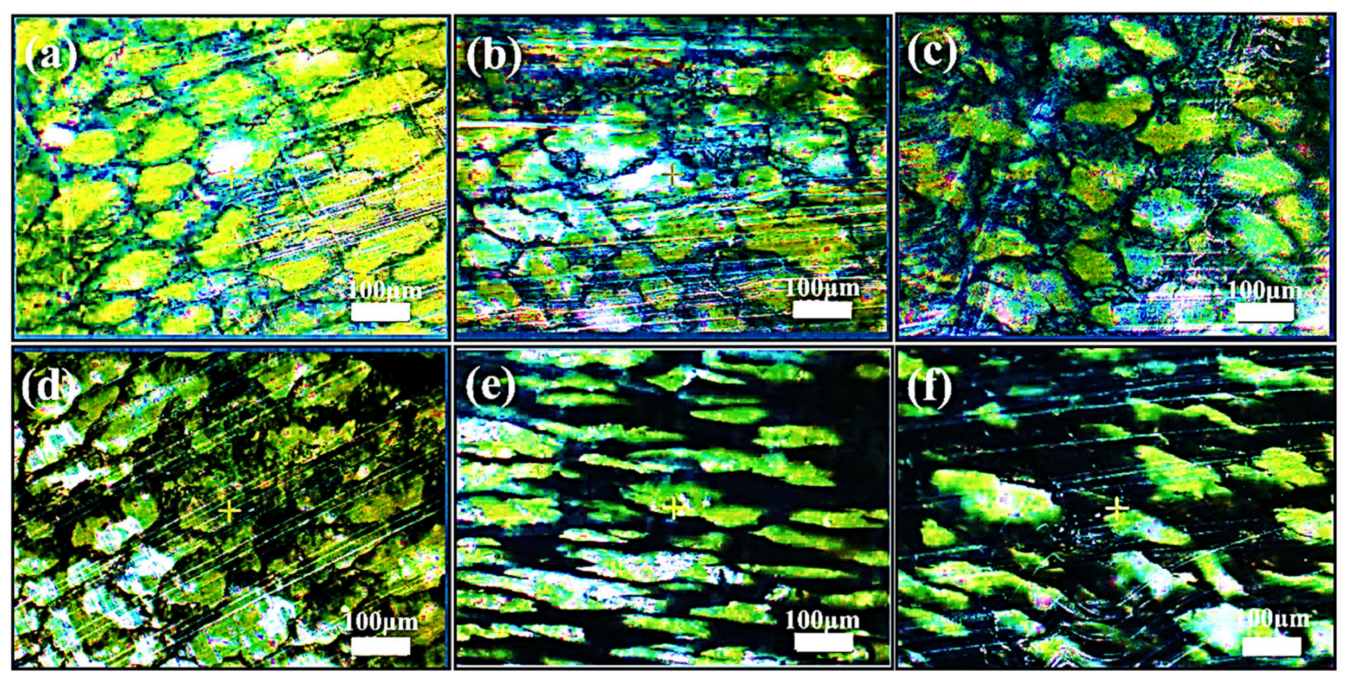

Figure 3. Optical microscopy images of the cross-sectional surface of UHMWPE/CCB composites: (a) UHMWPE/1-CCB 0.5 , (b)UHMWPE/1-CCB 1 , (c)UHMWPE/1-CCB $,(\mathbf{d}) \mathrm{UHMWPE} / \mathrm{h}-\mathrm{CCB}_{0.5},(\mathbf{e}) \mathrm{UHMWPE} / \mathrm{h}-\mathrm{CCB}_{1}$ and (f)UHMWPE/h-CCB .

Using a reasonable approach of revealing perfect interfacial bonding in between polymer domains is very important. Figure 4 displays the interfacial microstructure of UHMWPE/CCB composites. The cryo-fractured surface of UHMWPE/CCB composites appears obviously the segregated h-CCB or l-CCB particles located at the interface between adjacent UHMWPE granules. Moreover, the cryo-fractured surface morphology confirms that there are no obvious agglomerates and clusters across the whole cryo-fractured surfaces of two UHMWPE/CCB composites with higher CCB loading. In Figure $4 \mathrm{a}-\mathrm{c}$, the micrographs revealed that the 1-CCB dispersion and distribution morphology in UHMWPE/1-CCB composites with different l-CCB content is a relatively sparse morphology, the fractured surfaces become uneven, and some interfacial defects appear in the composites with the higher 1-CCB loading. In Figure 4a, the red circle indicated the recognized CCB particles, and the phenomena of the selective dispersion and distribution at the interface can be detected by a higher-magnification SEM image. With the increase of the addition of 1-CCB, from Figure $4 \mathrm{c}$ it can observed that 1-CCB conductive pathways between UHMWPE particles begin a loosely conductive networks at $3 \mathrm{wt} \% 1-\mathrm{CCB}$ concentration. With the CCB content increasing continually, many distinct interfacial voids appear in the cryo-fractured surfaces of UHMWPE composites with high l-CCB concentration. We can obviously observe some cracks of the composites with 5, 7, and $10 \mathrm{wt} \% 1-\mathrm{CCB}$ concentrations at higher magnifications, and two-phase interface of such composite is clear, which suggests the weak interfacial adhesion and compatibilization (Figure S2). This is attributed to the low specific surface area, poor polarity and physical adsorption ability of 1-CCB particles. By contrast, UHMWPE/h-CCB composite shows a unique dense segregated structure that $\mathrm{h}-\mathrm{CCB}$ are orderly distributed at the interfaces of UHMWPE granules. Moreover, the nanosized h-CCB particles are easily decorated onto UHMWPE granules due to their large specific surface area during the mechanical mixing, and then the rough UHMWPE granules experience the plastic deformation under hot-pressing stress, and constrain UHMWPE molecular chains diffusion in between granules. This synergistic interface effect forms a continuous and dense segregated structure in the process of compression molding. In Figure $4 d-f$, as the amount of h-CCB increases from 0.5 to $3.0 \mathrm{wt} \%$, we observed that both $\mathrm{h}-\mathrm{CCB}$ and 1-CCB particles were orderly dispersed at the interfaces of UHMWPE granules, this result is attributed to the strong volume exclusion effect of the UHMWPE matrix with high viscosity. Moreover, the SEM morphology images of UHMWPE/l-CCB and UHMWPE/h-CCB with 
different filler content are very similar, and no voids and interfacial defects are found. These results suggested that UHMWPE/l-CCB and UHMWPE/h-CCB composites have excellent mechanical properties at a low loading content. Meanwhile, beyond $3.0 \mathrm{wt} \%$ h-CCB content, a unique segregated h-CCB conductive network composed of the mixture of denser stacked h-CCB particles bridging UHMWPE matrix is observed, as seen in Figure S3 at higher magnifications. The evolution of various microstructures two kinds of UHMWPE/CCB composites is mainly attributed to the fabrication process of materials, and interface interactions of CCB-CCB and CCB-polymer matrix. In particular, different filler-matrix interfacial behavior was observed in the composites with CCB particles. In the composite with l-CCB particles, obvious gaps can be found, suggesting that the interactions between phases are relatively poor. By contrast, whereas the incorporation of h-CCB weight fraction into UHMWPE beyond $3 \mathrm{wt} \%$, a compact segregated conductive network between the UHMWPE boundary regions is constructed. Furthermore, the low ratios of h-CCB filled UHMWPE matrix not only greatly guarantees the mechanical properties of the composites, but also realizes the construction of the segregated structure at low conductive percolation threshold values of $0.5 \sim 1 \mathrm{wt} \%$.
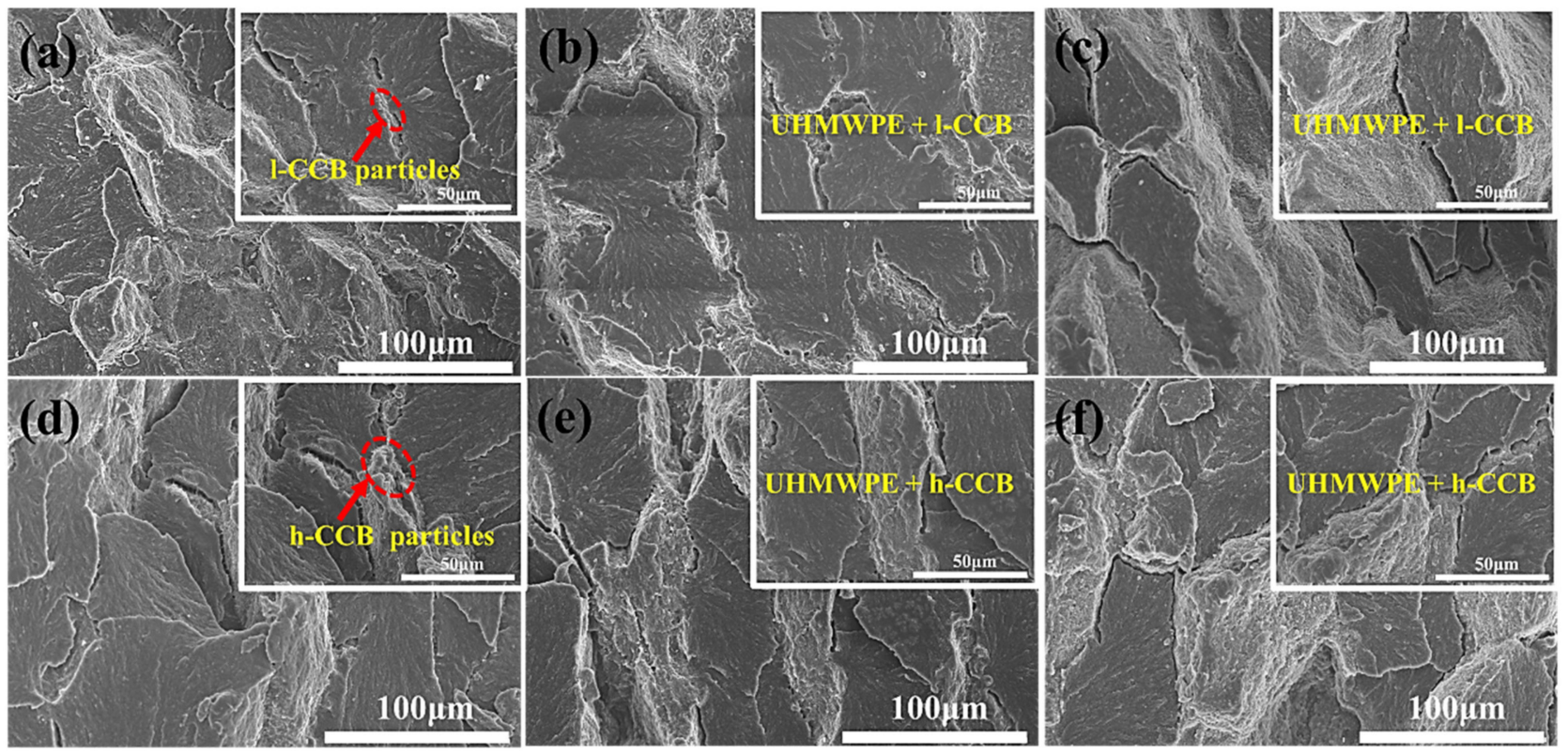

Figure 4. FE-SEM morphology of the cryo-fractured surface of UHMWPE/CCB composites: (a) UHMWPE/1-CCB 0.5 ; (b) UHMWPE/1-CCB $;$; (c) UHMWPE/1-CCB 3 ; (d) UHMWPE/h-CCB 0.5 ; (e) UHMWPE/h-CCB ; and (f) UHMWPE/h-CCB .

Raman spectroscopy is a fast and useful tool for the characterization of interface structure for carbon-filled polymer composites. To explore the orderly dispersion and distribution of carbon fillers in a polymer matrix, we analyze the interface transition layer structure of h-CCB and l-CCB filled UHMWPE composite via using Raman mapping measurements. Figure 5 shows the polymer-filler interface structure of Raman mapping surface morphology of different UHMWPE/CCB composites. As the CCB content increases from $1.0 \mathrm{wt} \%$ to $3.0 \mathrm{wt} \%$, we observed that the distribution of h-CCB or l-CCB significantly affects the interfacial layer microstructure of composite, owing to the formation of the different CCB networks. Moreover, the change of images color from red to blue represents of Raman signal of the UHMWPE matrix phase and CCB particles, respectively. The middle green color transition region is the UHMWPE-CCB co-existed phase, which becomes more and more distinct with the increase of h-CCB content, and in which a distinctly interfacial bonding layer is found. We also found that the segregated h-CCB lamella structures appear a compact segregated structure and interfacial bonding layer with different thicknesses, its $\mathrm{h}-\mathrm{CCB}$ lamella thickness mainly depends on the content of h-CCB, as observed on the crosssectional surface of UHMWPE/h-CCB composites as shown in Figure 5c,d. In Figure 5c,d, 
as the $\mathrm{h}-\mathrm{CCB}$ content increases from 1 to $3 \mathrm{wt} \%$, the thickness of the compact segregated h-CCB lamella increase from $4.44 \mu \mathrm{m}$ to $22.65 \mu \mathrm{m}$, while the interfacial bonding layer is slightly enhanced, but the increasing trend is no obvious. This implied the strong interfacial interactions of h-CCB and UHMWPE are very helpful for the interfacial structure and properties of the composites. To achieve deeper insights into the different interfacial effects of CCB-filled composites, we analyzed that the presence of different colors represents the different position of Raman spectrum in detail in Raman mapping images of UHMWPE/1$\mathrm{CCB}_{0.5}$, and UHMWPE/1-CCB 0.5 composites, as is shown in Figure S4a-c. Figure S4b-d displays the corresponding Raman spectrum of Raman mapping images of UHMWPE/1$\mathrm{CCB}_{0.5}$, and UHMWPE/1-CCB 0.5 composites at the position of UHMWPE matrix materials (A curve), UHMWPE-CCB interfaces (B curve) and CCB particles ( $C$ curve). We found that the h-CCB-UHMWPE interfacial structure significantly constrains UHMWPE molecular chains micromovement compared to $1-C C B$ particles, thereby leading to the conformational change of UHMWPE molecular chains in UHMWPE/h-CCB composites. This is related to the existence of the different interface bridging effects of 1-CCB-UHMWPE, h-CCBUHMWPE systems with the incorporation of CCB particles, which is consistent with SEM results. More importantly, the Raman spectrum of UHMWPE/h-CCB composite significantly presents an overlapped characteristic peak at $1348 \mathrm{~cm}^{-1}$ and $1587 \mathrm{~cm}^{-1}$. In Figure S4b-d, from this characteristic peak shift change of Raman spectrum of composites, the crystallinity of UHMWPE/h-CCB composite decreases with increasing h-CCB content, we speculated that the addition of h-CCB particles is likely to impact their conformational and crystalline structure of UHMWPE matrices. This further suggested that plentiful h-CCB nanoparticles as an enhanced transition layer is embedded into the UHMWPE matrices, which is contributed to the retention of the mechanical properties of high-loading polymeric-based composites.
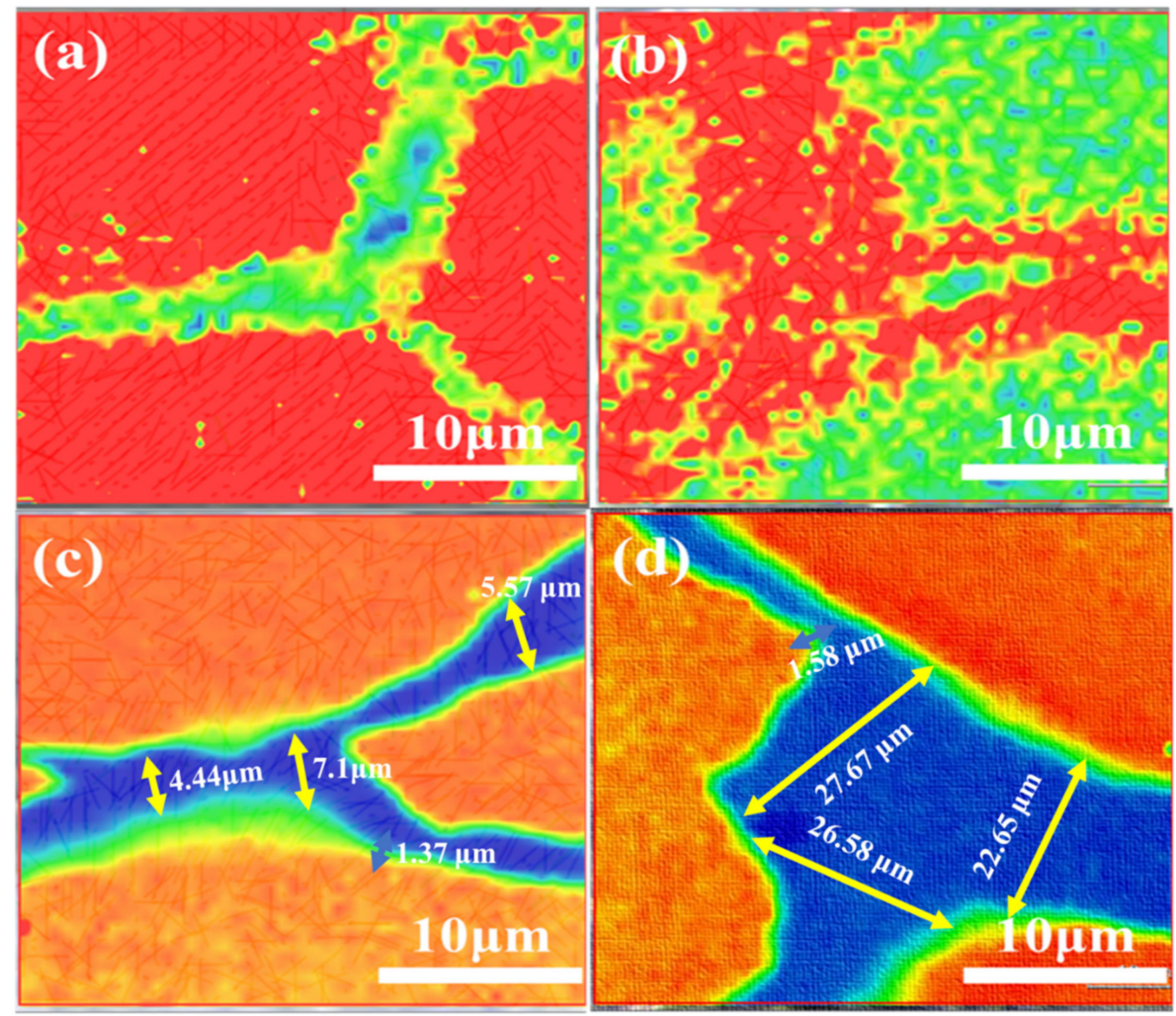

Correlation

\section{UHMWPE phase}

CCB phase

Figure 5. Raman mapping images of UHMWPE/CCB composites with different concentrations: (a) $\mathrm{UHMWPE} / 1-\mathrm{CCB}_{1}$; (b) UHMWPE/1-CCB 3 ; (c) UHMWPE/h-CCB 1 ; and (d) UHMWPE/h-CCB . 
DSC is one of the most effective methods for characterizing the effect of inorganic CCB in polymer matrices on the crystallization performance and the interaction of filler/polymer under the process of the crystallization of the crystal growth and nucleation. Therefore, further discussion on the thermal property parameters regarding the melting point $\left(\mathrm{T}_{\mathrm{m}}\right)$, enthalpy of fusion $\left(\Delta \mathrm{H}_{\mathrm{m}}\right)$ and crystallinity $\left(\chi_{\mathrm{c}}\right)$ are necessary. Figure S5 shows the DSC curves of pure UHMWPE, UHMWPE/1-CCB and UHMWPE/h-CCB composites. The detailed information of these DSC curves is listed in Table S2. In Table S2, the crystallinity $\left(\chi_{c}\right)$ of UHMWPE gradually decreases with an increase of CCB content, and the reason for the decrease is mainly ascribed to the extremely high viscosity of the UHMWPE matrix; rigid CCB particles are segregated and evenly dispersed in UHMWPE boundary regions due to the volume exclusion effect of the matrix, limiting the alignment of UHMWPE chains and decreasing the melting points $\left(\mathrm{T}_{\mathrm{m}}\right)$ of the obtained composites, which is consistent with the reported results of the crystallization properties of high specific surface area MWCNT/UHMWPE [36], large aspect ratio graphene nanoplatelets/UHMWPE [39] and multi-scale mesoporous structural bamboo charcoal/UHMWPE composites [40]. This result further confirms that the crystal structure of UHMWPE is influenced by the hCCB content-that is, physically interlocking interactions of high polar CCB particles impede the movement of UHMWPE molecular chains, which is also consistent with Raman mapping results. In Figure S5a, the melting curves of DSC find only one melting peak corresponding to that of UHMWPE, which indicates the incorporation of CCB does not affect the crystalline structure of UHMWPE. Besides, the obtained results from the cooling curves Figure S5b show the initial crystallization temperature $\left(\mathrm{T}_{\mathrm{c} \text {, onset }}\right)$ value of the crystallization temperature of UHMWPE is $121.16{ }^{\circ} \mathrm{C}$, while is no obvious change compared to UHMWPE/CCB composites. For instance, when CCB content is $5 \mathrm{wt} \%$, the Tc, onset of h-CCB or the l-CCB modified UHMWPE composites is 120.85 and $120.46{ }^{\circ} \mathrm{C}$, respectively, which is close to the initial crystallization temperature of pure UHMWPE $\left(121.16^{\circ} \mathrm{C}\right)$.

To obtain a better understanding the impact of the interfacial interactions of the addition of various CCB into UHMWPE matrix on the thermal stabilities of the composites, we further evaluate the incorporation of h-CCB and 1-CCB content on the thermal stabilities of the composites via using TGA analysis, separately. Figure S6 depicts pure UHMWPE, UHMWPE/h-CCB and UHMWPE/l-CCB composites of TGA curves and DTG curves. The relevant thermal data, including the temperature of $5,30,50 \%$ weight loss $\left(\mathrm{T}_{5}, \mathrm{~T}_{30}\right.$, and $\left.\mathrm{T}_{50}\right)$ of the composites, the temperature at maximum weight loss rate $\left(\mathrm{T}_{\max }\right)$, heat resistance index (HRI) and charred residue quality are summarized in Table S3. In Table S3, the initial decomposition temperature of UHMWPE/h-CCB and UHMWPE/1-CCB composites with $0.5 \mathrm{wt} \% \mathrm{CCB}$ concentration has been improved compared to pure UHMWPE, which is due to the interfacial bonding between polar CCB particles and UHMWPE granules, effectively hindering the transformation of heat in UHMWPE molecular chains, obviously enhancing their thermal stabilities. This result is consistent with the microstructure of the composite characterized by SEM. Moreover, the initial decomposition temperature of UHMWPE/h-CCB composites significantly increases as the h-CCB content increases compared to pure UHMWPE and UHMWPE/1-CCB, the $\mathrm{T}_{5}, \mathrm{~T}_{30}$ and $\mathrm{T}_{50}$ of UHMWPE/h$\mathrm{CCB}_{10}$ composites are increased by $9.67,11.5$ and $13.19^{\circ} \mathrm{C}$, respectively. This is attributed to high-quality CCB network structures that play a thermal barrier role, restrict the heat transfer in the UHMWPE matrix and simultaneously delay the thermal decomposition progress of composites as well. Furthermore, the $T_{5}, T_{30}, T_{50}$ and heat resistance index (HRI) of UHMWPE/h-CCB composites is greater than UHMWPE/1-CCB composites, and these results further illustrate that $\mathrm{h}-\mathrm{CCB}$ particles are conducive to enhance the interface effect and thermal stability properties of composites.

\subsection{Mechanical Properties}

The mechanical properties of most polymer composites rely on various factors, including polymer/filler type, method of preparation, dispersion or distribution of fillers [41] and 
polymer-filler interfacial interaction [42]. In addition, the excellent mechanical properties play an important role in the industrial practical applications of shielding materials as well. It is well-known that the mechanical performance is predominately determined by the interfacial adhesion of the adjacent polymer domains in CPCs materials [43]. Figure 6 shows the mechanical properties of pure UHMWPE, UHMWPE/h-CCB and UHMWPE/1-CCB composites. In Figure 6, when CCB content is $1 \mathrm{wt} \%$, it can be seen that UHMWPE/CCB composites show higher mechanical properties compared to pure UHMWPE, due to the incorporation of good-dispersion CCB particles into UHMWPE matrices as nucleating agents [24], resulting in the stable conformation of the UHMWPE macular chains. Moreover, high loading UHMWPE/h-CCB composites greatly maintain mechanical performance compared to the same addition of UHMWPE/1-CCB composites, the elongation at break value of UHMWPE/h-CCB composites is also significantly higher than that of UHMWPE/l-CCB composites, further suggesting the interfacial adhesion of h-CCB nanoparticles is superior to the interaction of 1-CCB, Furthermore, when the increase of h-CCB or 1-CCB content to $10 \mathrm{wt} \%$, the tensile strength and elongation at break value of UHMWPE/h-CCB composites are approximately two and six times that of UHMWPE/1-CCB composites, separately, as shown in Figure 6. The mechanical properties improvement in the strength and fracture of high-loading UHMWPE/h-CCB composite is thus attributed to the strong mechanical interlocking in between adjacent UHMWPE granules and h-CCB nanoparticles, good wetting interactions of $\mathrm{h}-\mathrm{CCB}$ nanoparticles, leading to forming the dense and rigid $\mathrm{h}-\mathrm{CCB}$ particle networks that can greatly transfer stress and dissipate energy [44]. Numerous matrix fibrils are formed on the tensile fractured surface of UHMWPE/h-CCB composite, and a typical ductile fracture is found. Figure S7 further demonstrated that endowing the good interfacial adhesion between UHMWPE and h-CCB nanoparticles, making the UHMWPE/h-CCB composite more competitive as segregated conductive polymer materials, which can resist high stress in some specific fields. These results are consistent with the above-obtained SEM, OM, Raman mapping imaging and TGA characterization results.
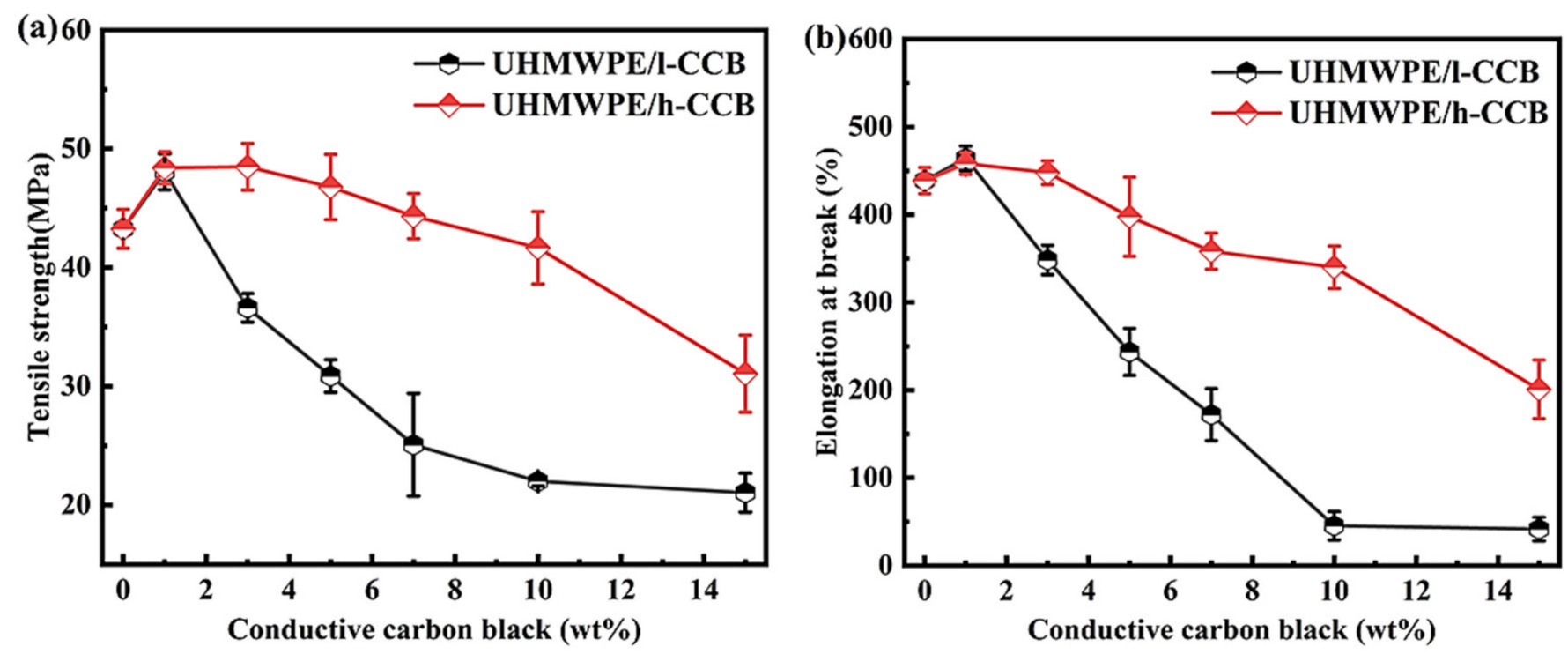

Figure 6. (a) tensile strength and (b) elongation at break of UHMWPE/CCB composites.

To further elucidate fracture and enhancement mechanism, the tensile fractured surfaces of UHMWPE/h-CCB, and UHMWPE/l-CCB composites, Figure 7 presents the broken tensile surfaces of 1-CCB particles filled UHMWPE-based composite compared to a unique UHMWPE/h-CCB composite. The surface on the composite surface is rough because of the presence of h-CCB nanoparticles. No obvious h-CCB particles agglomeration can be observed in the composites, indicating that the dry-blending technique is an effective method to uniformly disperse the h-CCB particles in the polymer matrix. Figure 7a-c show that the surface of the composite material had some small voids, and some l-CCB particles 
are not well dispersed in the matrix, which was due to the poor interfacial mechanically interlocked in UHMWPE matrix, resulting in the decrease of mechanical properties of composites. Meanwhile, Figure 7d-f show that good interface quality is produced — that is, perfect contact is observed (no voids).
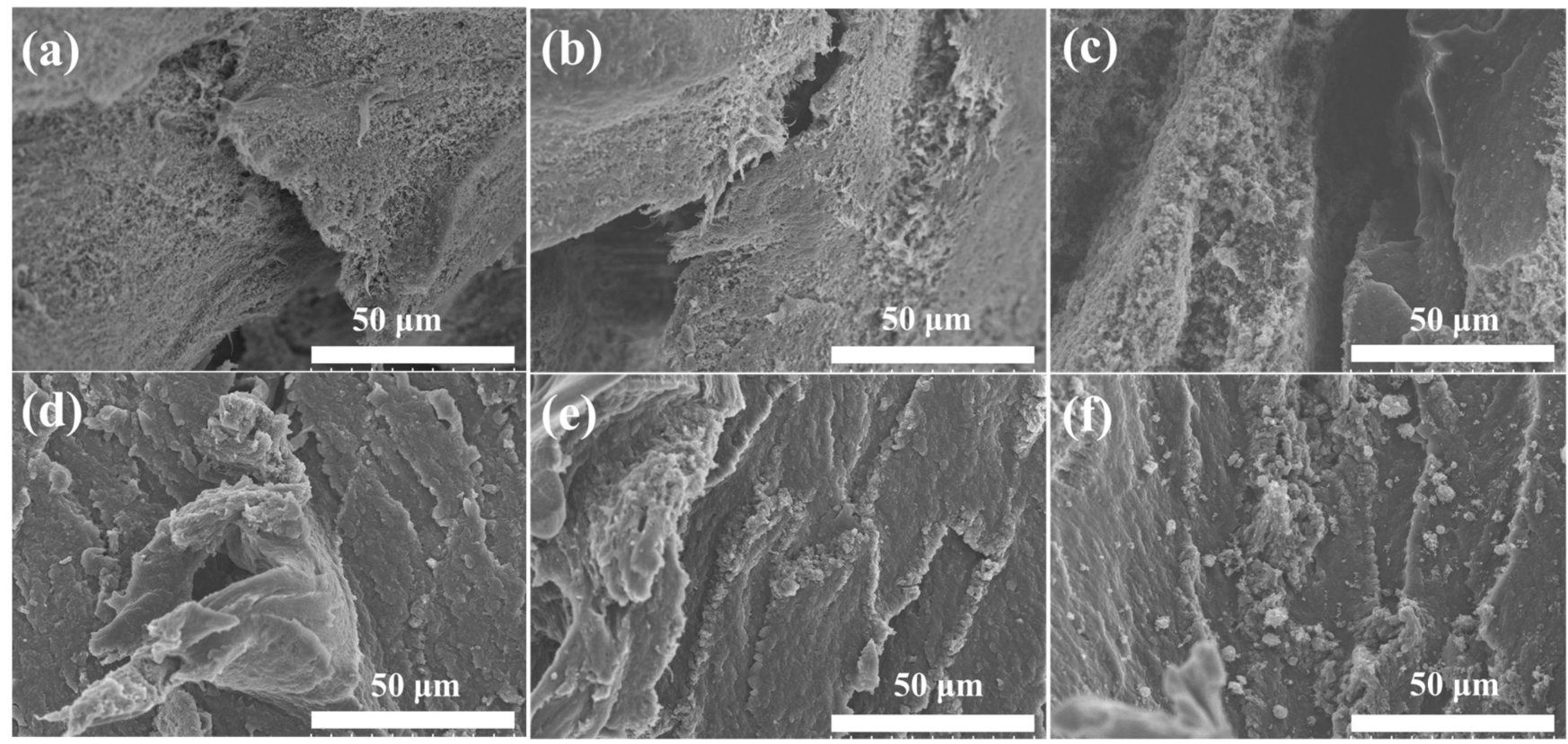

Figure 7. SEM images of the tensile fractured surfaces of UHMWPE/l-CCB composites: (a) UHMWPE/1-CCB ; $^{-}$ (b) UHMWPE/1-CCB 10 ; and (c) UHMWPE/1-CCB 15 , and UHMWPE/h-CCB composites: (d) UHMWPE/h-CCB ; (e) UHMWPE/h-CCB 10 ; and (f) UHMWPE/h-CCB 15 .

\subsection{Electrical Conductivity}

As one of the key parameters of the electromagnetic interference (EMI) shielding material, high electrical conductivity $(\sigma)$ plays a vital role in EMI shielding application materials. Figure 8 shows the $\sigma$ of UHMWPE/h-CCB and UHMWPE/1-CCB composites. In Figure $8 \mathrm{a}, \mathrm{b}$, the $\sigma$ increases gradually with the increase of h-CCB or 1-CCB loading weight ratios. Moreover, UHMWPE/h-CCB composites possess a higher $\sigma$ than that of UHMWPE/1-CCB composites with the same concentration, which should be attributed to the improved conductive network of h-CCB particles. Besides, according to theoretical percolation threshold $[45,46]: \sigma=\sigma_{0}\left(\varphi-\varphi_{\mathrm{c}}\right)^{\mathrm{t}}$, for $\varphi>\varphi_{\mathrm{c}}$, where $\varphi$ is the volume fraction of the fillers, $\varphi_{\mathrm{c}}$ is the volume percolation concentration, $\sigma$ and $\sigma_{0}$ represents the electrical conductivity of the composites and the conducting fillers, respectively. $t$ represents a critical exponent reflecting the dimensionality of the system. To obtain the $\varphi_{\mathrm{c}}$ value, the linear fits of $\log \sigma$ vs. $\log \left(\varphi-\varphi_{c}\right)$ is performed for each estimated " $\varphi_{\mathrm{c}}$ ", as presented in the interior illustration of Figure $8 \mathrm{~b}$, and it is found that $\varphi_{\mathrm{c}}$ value of UHMWPE/h-CCB is far less than UHMWPE/1-CCB composite, and the percolation threshold of UHMWPE/h-CCB composite is $0.49 \mathrm{wt} \%$. In comparison, we also found that the $\sigma$ values of UHMWPE/1-CCB composites as a function of CCB content display a linear increasing trend, the estimated percolation threshold value of UHMWPE/1-CCB composite is more than $5 \mathrm{wt} \%$. The $\varphi_{\mathrm{c}}$ value UHMWPE/h-CCB composite is far lower than that of UHMWPE/1-CCB composite. Furthermore, UHMWPE/h-CCB 10 already gains a desirable electrical conductivity, and it is exciting that an excellent $\sigma$ of UHMWPE/h-CCB composites $(0.12 \mathrm{~S} / \mathrm{cm})$ with low $\mathrm{h}$-CCB loading of $10 \mathrm{wt} \%$ far exceeds the target value $\left(1.31 \times 10^{-2} \mathrm{~S} / \mathrm{cm}\right)$ for commercial use as EMI shielding materials, which can fulfill the commercial EMI shielding application. The achievement of outstanding $\sigma$ values in UHMWPE/h-CCB 10 can be correlated with the different CCB networks formed in the UHMWPE matrix. For UHMWPE/h-CCB 10 composites, the formation of the interconnecting and dense network reveals that a large 
number of h-CCB are concentrated at the interfaces of UHMWPE domains and closely overlapped, which is more conducive to the transmission of electrons and interfacial polarity. Moreover, for UHMWPE/1-CCB 10 composites, the $\sigma$ values of UHMWPE/1-CCB 10 composites mainly rely on 1-CCB loading to realize higher $\sigma$ owing to inherent $1-C C B^{\prime}$ s low electrical conductivity and poor interfacial energy characteristics. To further demonstrate the potential application of conductive UHMWPE/CCB composites, in Figure 8c, d a basic electronic setup based on a light-emitting diode (LED), together with various conductive UHMWPE/CCB composites, was assembled. The circuit measurement was carried out in UHMWPE/h-CCB 3 composite and UHMWPE/1-CCB 7 composite, and as expected, the LED bulbs can be glowed by the circuit, demonstrating the percolation behavior of UHMWPE/h-CCB segregated composite at a low percolation threshold, and have desirable $\sigma$ value. Overall, utilizing an appropriate amount of CCB can not only realize high performance simultaneously, but also achieve the EMI materials with excellent EMI SE.
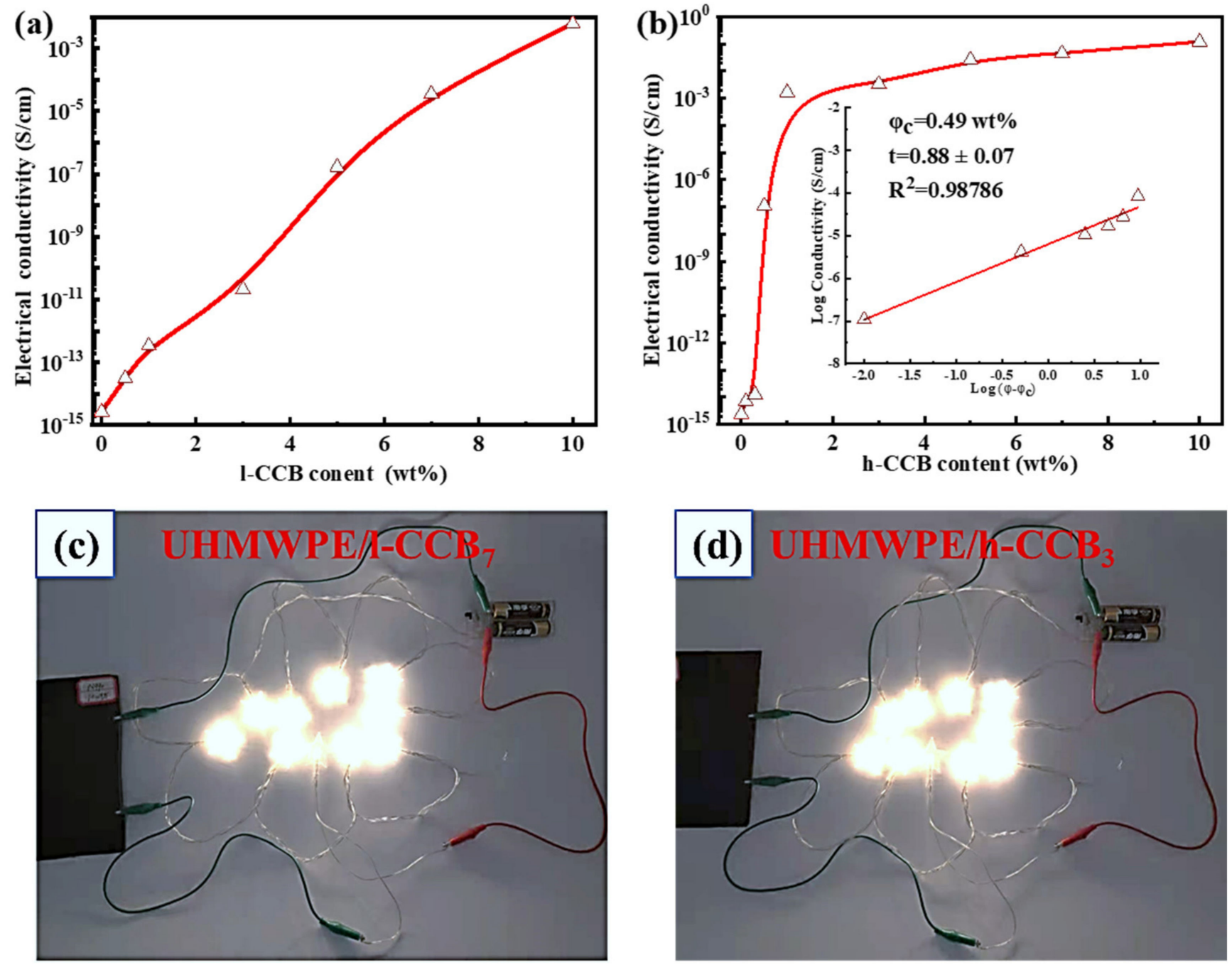

Figure 8. Comparation of $\sigma$ of UHMWPE/CCB composites with the different CCB content: (a) UHMWPE/h-CCB; and (b) UHMWPE/1-CCB; the actual conductive circuit of the glowing LED bulbs energized by (c) UHMWPE/1-CCB ; and (d) UHMWPE/h-CCB 3 composite.

\subsection{Electromagnetic Interference (EMI) Shielding Performance}

Figure 9a-f displays the EMI shielding performance and EMI shielding mechanism diagram of segregated UHMWPE/1-CCB and UHMWPE/h-CCB composites with different CCB content. In Figure 9a, it is clear that the EMI SE are continuously improved with increasing CCB filler loading due to the improvement in well-connected conductive net- 
work and electrical conductivity in the UHMWPE matrix. For instance, at $10 \mathrm{wt} \% \mathrm{~h}-\mathrm{CCB}$ content, the EMI SE of the UHMWPE/h-CCB 10 composite is found to be a satisfactory EMI $\mathrm{SE}$ of $22.3 \mathrm{~dB}$ at $\mathrm{X}$ band (8.2-12.4 GHz), and which already exceeded the requirement for commercial EMI SE (20 dB) - this signifies 99.9\% blocking of the EM wave. Moreover, in Figure $9 \mathrm{a}$, we found that the extent of increase in EMI SE corresponds to the extent of h-CCB incorporated in the UHMWPE matrix. The incorporation of h-CCB in UHMWPE matrix is the most significant contributor to the EMI SE of the composite compared to UHMWPE/1CCB composite. To comprehend the EMI shielding mechanism for the UHMWPE/h-CCB composite composites, the contribution of absorption $\mathrm{SE}\left(\mathrm{SE}_{\mathrm{A}}\right)$ and reflection $\mathrm{SE}\left(\mathrm{SE}_{\mathrm{R}}\right)$ is disassembled from the total $\mathrm{SE}\left(\mathrm{SE}_{\mathrm{T}}\right)$, and is shown in Figure $9 \mathrm{~b}-\mathrm{d}$. The detailed $\mathrm{SE}_{\mathrm{A}}$, $\mathrm{SE}_{\mathrm{R}}$ and $\mathrm{SE}_{\mathrm{T}}$ Values at $8.2 \mathrm{GHz}$ are summarized in Table $\mathrm{S} 4$. The relationship between power coefficients [i.e., reflection (R), absorption (A) and Transmission (T)] and frequency of the segregated UHMWPE/1-CCB 15 and UHMWPE/h-CCB 15 composites is illustrated in Figure S8. For UHMWPE/h-CCB 15 composite, the $\mathrm{R}$ value raises to 0.78 , and the $\mathrm{T}$ value keeps at quite a low level. A gradually decreasing trend is observed for A values caused by the huge increase of R. Meanwhile, the UHMWPE/1-CCB 15 shows a low $R$ value of 0.49 at $8.2 \mathrm{GHz}$. Moreover, from Figure 9, it could be significantly observed that $\mathrm{SE}_{\mathrm{A}}$ contributes overwhelmingly to $\mathrm{SE}_{\mathrm{T}}$, and this result suggests that absorption is the dominant shielding mechanism. Furthermore, we use the mechanism diagram to vividly show the entire process of electromagnetic waves passing through the composites, as shown in Figure 9e,f. The main way for UHMWPE/h-CCB composites to shield EM waves is absorption. When the electromagnetic wave reaches the surface of the composites, part of the electromagnetic wave is reflected, owing to the impedance mismatch. According to the impedance mismatch theory, the EMI SE of the segregated CPCs crucially depends on its high electrical loss and interfacial polarization loss. The desirable EMI shielding performance of CPCs often occurs synchronously with high electrical conductivity. The strong interfacial interaction and compatibility between h-CCB-h-CCB, h-CCB-UHMWPE is usually beneficial to forming more continuous conductive paths and subtle interface polarization, leading to the low percolation threshold and high EMI SE. Moreover, the obtained plentiful interconnecting conductive paths can impact the electrical conductivity of composite and decrease the separation distance between conductive fillers to a great extent. Overall, the high EMI SE of the segregated UHMWPE/CCB composites is attributed to such a dense conductive network with the fine interfacial bonding interactions-such interactions generate electrical loss and polarization loss, leading to the strong absorption and multiple scattering of incident EM waves. 

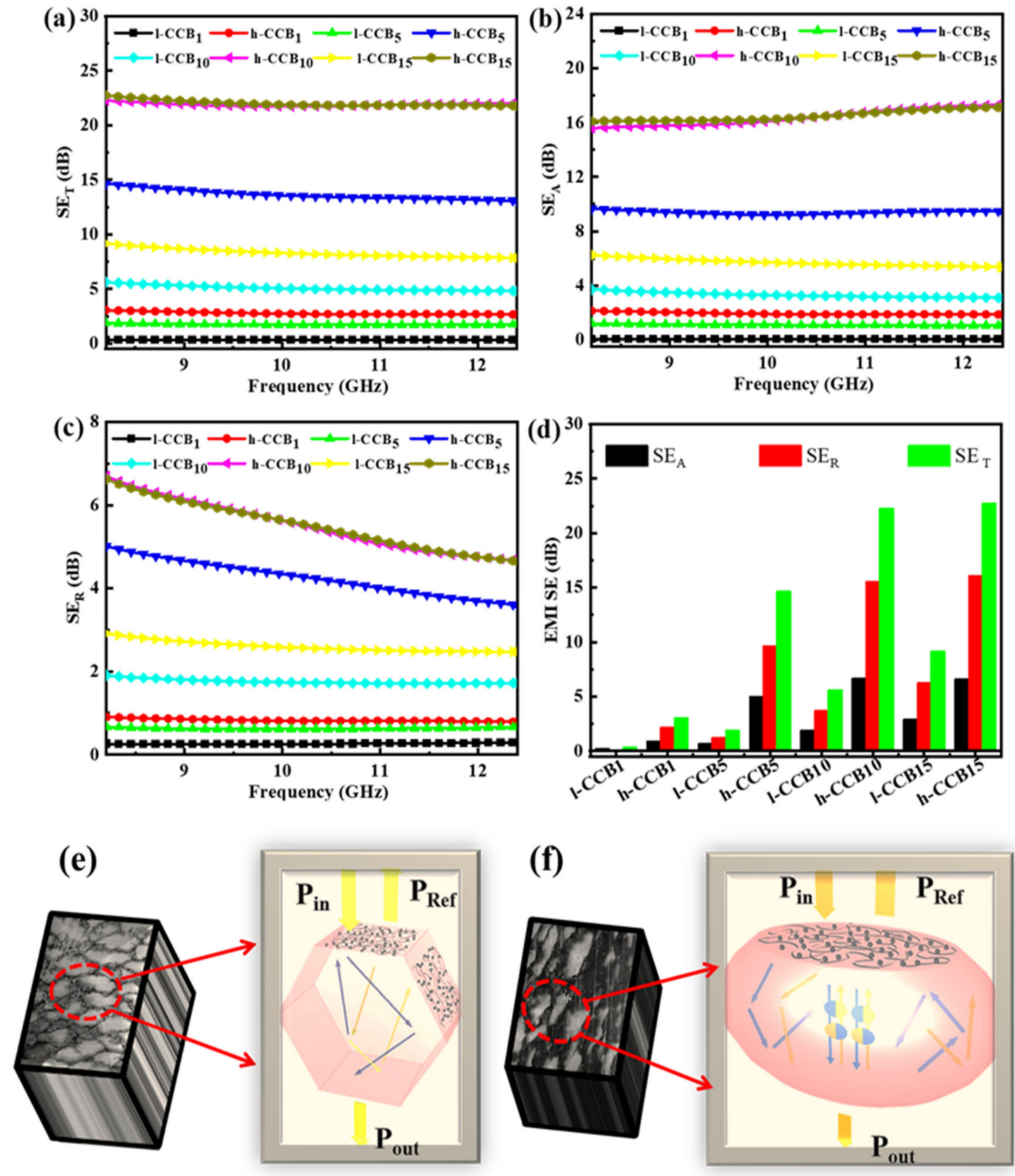

Figure 9. (a) $\mathrm{SE}_{\mathrm{T}}$; (b) $\mathrm{SE}_{\mathrm{A}}$; and (c) $\mathrm{SE}_{\mathrm{R}}$ of UHMWPE/h-CCB and UHMWPE/1-CCB composites with different CCB contents; as well as (d) Comparison of EMI SE of UHMWPE/h-CCB and UHMWPE/1-CCB composites with different CCB weight ratios at the thickness of approximately $1.5 \mathrm{~mm}$; (e) EMI shielding mechanism diagram of UHMWPE/1-CCB; and (f) UHMWPE/h-CCB composites.

\section{Conclusions}

UHMWPE/h-CCB and UHMWPE/l-CCB composites were prepared using simple and effective high-speed mechanical mixing combined with the compression molding method. The mechanical properties of high-loading UHMWPE/h-CCB composite were maintained greatly, and much higher than that of UHMWPE/1-CCB composite, revealing the strong interfacial interactions of UHMWPE matrix and h-CCB particles. The electrical threshold mechanism reveals that a low percolation threshold $(0.49 \mathrm{wt} \%)$ is obtained in the UHMWPE/h-CCB composite due to the formation of a densely compacted h-CCB network, which is far lower than that of the percolation threshold of UHMWPE/1-CCB. UHMWPE/h-CCB exhibits an evident improvement of electromagnetic interference shield- 
ing effectiveness (EMI SE) when the dosage of h-CCB exceeds its electrical percolation threshold, the UHMWPE/h-CCB composite exhibits a satisfactory EMI SE value of $22.3 \mathrm{~dB}$ at $10 \mathrm{wt} \% \mathrm{~h}-\mathrm{CCB}$ content, which is as four times that of UHMWPE/l-CCB composite with same 1-CCB dosage $(5.6 \mathrm{~dB})$. Moreover, the tensile strength and elongation at break value of UHMWPE/h-CCB 10 composites are approximately two and six times that of UHMWPE/1-CCB 10 composites. In a word, the addition of h-CCB particles not only effectively increases the thermal stability of segregated conducting UHMWPE-based composite, but also ensures the excellent mechanical properties and acceptable EMI SE in practical applications. This low-cost and high-performance segregated conductive polymer composite is a promising candidate for EMI shielding and antistatic fields, which will expect to open the door for next-generation cost-effective EMI shielding materials to cater academic and industrial applications in the future.

Supplementary Materials: The following are available online at https: / www.mdpi.com/article/ 10.3390/nano11082074/s1. Figure S1. Pore size distributions of h-CCB and 1-CCB nanoparticles, Figure S2. SEM morphologies of quenched section of the segregated UHMWPE composites with the different l-CCB content: (a) UHMWPE/1-CCB 5 , (b) UHMPWPE/1-CCB Figure S3. SEM morphologies of quenched section of the segregated UHMWPE composites with the different h-CCB content: (a) UHMWPE/h-CCB, , (b) UHMWPE/h-CCB 7 , (c) UHMWPE/h-CCB 10 , Figure S4. (a) Raman mapping images of the UHMWPE/1-CCB 0.5 composites, and (b) the corresponding Raman spectrum of comparation of UHMWPE/1-CCB $\mathrm{CC}_{0.5}$ composite at the different position of Raman mapping images, (c) Raman mapping images of UHMWPE/h-CCB 0.5 composite, and (d) the corresponding Raman spectrum of comparation of UHMWPE/h-CCB $\mathrm{CH}_{0.5}$ composite at the different position of Raman mapping images. Figure S5. DSC curves of pure UHMWPE, UHMWPE/1-CCB and UHMWPE/h-CCB composites: (a) second heating curved; (b) cooling curved, Figure S6. (a) TGA and (b) DTA curved of UHMWPE, UHMWPE/h-CCB and UHMWPE/1-CCB composites under nitrogen atmosphere, Figure S7. SEM micrographs of the tensile fractured surface of UHMWPE/1-CCB, and UHMWPE/h-CCB composites: (a) UHMWPE/1-CCB 10 , (b) UHMWPE/1-CCB 15 , (c) UHMWPE/h$\mathrm{CCB}_{10}$, (d) UHMWPE/h-CCB 15 , Figure S8. Relationship between power coefficients and frequency of the segregated (a) UHMWPE/h-CCB 15 and (b) UHMWPE/1-CCB 15 composites, Table S1. Physical properties of two types of conductive carbon black (CCB) nanoparticles, Table S2. DSC values of pure UHMWPE, UHMWPE/1-CCB and UHMWPE/h-CCB composites, Table S3. Thermal stabilities of pure UHMWPE, UHMWPE/h-CCB and UHMWPE/1-CCB composites obtained from TGA curves, Table S4. Comparison of $\mathrm{SE}_{\mathrm{T}}, \mathrm{SE}_{\mathrm{R}}$, and $\mathrm{SE}_{\mathrm{A}}$ at the frequency of $8.2 \mathrm{GHZ}$ for UHMWPE/1-CCB and UHMWPE/h-CCB composites.

Author Contributions: Conceptualization, C.C. and Q.Q.; methodology, H.C.; validation, B.H., X.S. and L.X.; formal analysis, C.C.; investigation, H.C.; resources, Q.C.; data curation, H.C.; writingoriginal draft preparation, H.C.; writing-review and editing, C.C.; supervision, Q.Q. and X.S.; project administration, Q.C.; funding acquisition, Q.Q. All authors have read and agreed to the published version of the manuscript.

Funding: The study was funded by the grant from the National Key Research and Development Program of China (No. 2016YFB0302300).

Data Availability Statement: Data is contained within the article and Supplementary Materials.

Conflicts of Interest: The authors declare no conflict of interest.

\section{References}

1. Kumar, P.; Narayan Maiti, U.; Sikdar, A.; Kumar Das, T.; Kumar, A.; Sudarsan, V. Recent advances in polymer and polymer composites for electromagnetic interference shielding: Review and future prospects. Polym. Rev. 2019, 59, 687-738. [CrossRef]

2. Jiang, D.; Murugadoss, V.; Wang, Y.; Lin, J.; Ding, T.; Wang, Z.; Shao, Q.; Wang, C.; Liu, H.; Lu, N.; et al. Electromagnetic interference shielding polymers and nanocomposites-A review. Polym. Rev. 2019, 59, 280-337. [CrossRef]

3. Wanasinghe, D.; Aslani, F. A review on recent advancement of electromagnetic interference shielding novel metallic materials and processes. Compos. Part B 2019, 176, 107207. [CrossRef]

4. Zhao, B.; Hamidinejad, M.; Wang, S.; Bai, P.; Che, R.; Zhang, R.; Park, C.B. Advances in electromagnetic shielding properties of composite foams. J. Mater. Chem. A 2021, 9, 8896-8949. [CrossRef] 
5. Zhang, W.; Wei, L.; Ma, Z.; Fan, Q.; Ma, J. Advances in waterborne polymer/carbon material composites for electromagnetic interference shielding. Carbon 2021, 177, 412-426. [CrossRef]

6. Zhang, C.; Lv, Q.; Liu, Y.; Wang, C.; Wang, Q.; Wei, H.; Liu, L.; Li, J.; Dong, H. Rational design and fabrication of lightweight porous polyimide composites containing polyaniline modified graphene oxide and multiwalled carbon nanotube hybrid fillers for heat-resistant electromagnetic interference shielding. Polymer 2021, 224, 123742. [CrossRef]

7. Yao, Y.; Jin, S.; Zou, H.; Li, L.; Ma, X.; Lv, G.; Gao, F.; Lv, X.; Shu, Q. Polymer-based lightweight materials for electromagnetic interference shielding: A review. J. Mater. Sci. 2021, 56, 6549-6580. [CrossRef]

8. Xu, H.; Li, Y.; Han, X.; Cai, H.; Gao, F. Carbon black enhanced wood-plastic composites for high-performance electromagnetic interference shielding. Mater. Lett. 2021, 285, 129077. [CrossRef]

9. Wu, N.; Hu, Q.; Wei, R.; Mai, X.; Naik, N.; Pan, D.; Guo, Z.; Shi, Z. Review on the electromagnetic interference shielding properties of carbon based materials and their novel composites: Recent progress, challenges and prospects. Carbon 2021, 176, 88-105. [CrossRef]

10. Liang, J.; Chen, J.; Shen, H.; Hu, K.; Zhao, B.; Kong, J. Hollow porous bowl-like nitrogen-doped cobalt/carbon nanocomposites with enhanced electromagnetic wave absorption. Chem. Mater. 2021, 33, 1789-1798. [CrossRef]

11. Xiao, W.; Han, X.; Niu, X.; Lin, J.; Han, X.; He, A.; Jiang, Q.; Nie, H. Hierarchical porous carbon nanotube skeleton supported polydimethylsiloxane composite with electrical continuity for high-performance electromagnetic shielding. Adv. Mater. Technol. 2021, 2100013. [CrossRef]

12. Li, X.; Wang, G.; Yang, C.; Zhao, J.; Zhang, A. Mechanical and EMI shielding properties of solid and microcellular TPU/nanographite composite membranes. Polym. Test. 2021, 93, 106891. [CrossRef]

13. Deng, H.; Lin, L.; Ji, M.; Zhang, S.; Yang, M.; Fu, Q. Progress on the morphological control of conductive network in conductive polymer composites and the use as electroactive multifunctional materials. Prog. Polym. Sci. 2014, 39, 627-655. [CrossRef]

14. Pang, H.; Xu, L.; Yan, D.-X.; Li, Z.-M. Conductive polymer composites with segregated structures. Prog. Polym. Sci. 2014, 39, 1908-1933. [CrossRef]

15. Song, P.; Liu, L.; Fu, S.; Yu, Y.; Jin, C.; Wu, Q.; Zhang, Y.; Li, Q. Striking multiple synergies created by combining reduced graphene oxides and carbon nanotubes for polymer nanocomposites. Nanotechnology 2013, 24, 125704. [CrossRef]

16. Song, P.; Cao, Z.; Cai, Y.; Zhao, L.; Fang, Z.; Fu, S. Fabrication of exfoliated graphene-based polypropylene nanocomposites with enhanced mechanical and thermal properties. Polymer 2011, 52, 4001-4010. [CrossRef]

17. Liu, S.; Qin, S.; Jiang, Y.; Song, P.; Wang, H. Lightweight high-performance carbon-polymer nanocomposites for electromagnetic interference shielding. Compos. Part A Appl. Sci. Manuf. 2021, 145. [CrossRef]

18. Yu, W.C.; Zhang, G.Q.; Liu, Y.H.; Xu, L.; Yan, D.X.; Huang, H.D.; Tang, J.H.; Xu, J.Z.; Li, Z.M. Selective electromagnetic interference shielding performance and superior mechanical strength of conductive polymer composites with oriented segregated conductive networks. Chem. Eng. J. 2019, 373, 556-564. [CrossRef]

19. Jia, L.-C.; Yan, D.-X.; Cui, C.-H.; Ji, X.; Li, Z.-M. A Unique double percolated polymer composite for highly efficient electromagnetic interference shielding. Macromol. Mater. Eng. 2016, 301, 1232-1241. [CrossRef]

20. Zhang, Q.; Wang, J.; Guo, B.-H.; Guo, Z.-X.; Yu, J. Electrical conductivity of carbon nanotube-filled miscible poly(phenylene oxide)/polystyrene blends prepared by melt compounding. Compos. Part B Eng. 2019, 176, 107213. [CrossRef]

21. Feng, D.; Wang, Q.; Xu, D.; Liu, P. Microwave assisted sinter molding of polyetherimide/carbon nanotubes composites with segregated structure for high-performance EMI shielding applications. Compos. Sci. Technol. 2019, 182, 107753. [CrossRef]

22. Jia, L.C.; Yan, D.X.; Jiang, X.; Pang, H.; Gao, J.F.; Ren, P.G.; Li, Z.M. Synergistic effect of graphite and carbon nanotubes on improved electromagnetic interference shielding performance in segregated composites. Ind. Eng. Chem. Res. 2018, 57, 11929-11938. [CrossRef]

23. Cui, C.-H.; Yan, D.-X.; Pang, H.; Jia, L.-C.; Bao, Y.; Jiang, X.; Li, Z.-M. Towards efficient electromagnetic interference shielding performance for polyethylene composites by structuring segregated carbon black/graphite networks. Chin. J. Polym. Sci. 2016, 34, 1490-1499. [CrossRef]

24. Cheng, H.; Cao, C.; Zhang, Q.; Wang, Y.; Liu, Y.; Huang, B.; Sun, X.-L.; Guo, Y.; Xiao, L.; Chen, Q.; et al. Enhancement of electromagnetic interference shielding performance and wear resistance of the UHMWPE/PP blend by constructing a segregated hybrid conductive carbon black-polymer network. ACS Omega 2021, 6, 15078-15088. [CrossRef] [PubMed]

25. Wang, Y.; Yang, J.; Zhou, S.; Zhang, W.; Chuan, R. Electrical properties of graphene nanoplatelets/ultra-high molecular weight polyethylene composites. J. Mater. Sci. Mater. Electron. 2017, 29, 91-96. [CrossRef]

26. Dyachkova, T.; Gutnik, I.; Nagdaev, V.; Maksimkin, A.; Burakova, E.; Galunin, E.; Memetov, N.; Khan, Y.; Dayyoub, T. Studying the surface of UHMWPE films modified with graphene nanoplatelets using a Raman mapping method. Fuller. Nanotub. Carbon Nanostruct. 2020, 28, 561-564. [CrossRef]

27. Sun, Z.-F.; Ren, P.-G.; Zhang, Z.-W.; Ren, F. Synergistic effects of conductive carbon nanofillers based on the ultrahigh-molecularweight polyethylene with uniform and segregated structures. J. Appl. Polym. Sci. 2019, 136, 47317. [CrossRef]

28. Pang, H.; Yan, D.X.; Bao, Y.; Chen, J.B.; Chen, C.; Li, Z.M. Super-tough conducting carbon nanotube/ultrahigh-molecular-weight polyethylene composites with segregated and double-percolated structure. J. Mater. Chem. 2012, 22, 23568-23575. [CrossRef]

29. Mondal, S.; Ravindren, R.; Shin, B.; Kim, S.; Lee, H.; Ganguly, S.; Das, N.C.; Nah, C. Electrical conductivity and electromagnetic interference shielding effectiveness of nano-structured carbon assisted poly(methyl methacrylate) nanocomposites. Polym. Eng. Sci. 2020, 60, 2414-2427. [CrossRef] 
30. Huang, C.J.; Cheng, Q.F. Learning from nacre: Constructing polymer nanocomposites. Compos. Sci. Technol. 2017, 150, 141-166. [CrossRef]

31. Zeng, H.; Wu, J.; Pei, H.; Zhang, Y.; Ye, Y.; Liao, Y.; Xie, X. Highly thermally conductive yet mechanically robust composites with nacre-mimetic structure prepared by evaporation-induced self-assembly approach. Chem. Eng. J. 2021, 405, 126865. [CrossRef]

32. Zhang, T.; Sun, J.; Ren, L.; Yao, Y.; Wang, M.; Zeng, X.; Sun, R.; Xu, J.-B.; Wong, C.-P. Nacre-inspired polymer composites with high thermal conductivity and enhanced mechanical strength. Compos. Part A Appl. Sci. Manuf. 2019, 121, 92-99. [CrossRef]

33. Zhu, S.; Shi, R.; Qu, M.; Zhou, J.; Ye, C.; Zhang, L.; Cao, H.; Ge, D.; Chen, Q. Simultaneously improved mechanical and electromagnetic interference shielding properties of carbon fiber fabrics/epoxy composites via interface engineering. Compos. Sci. Technol. 2021, 207, 108696. [CrossRef]

34. Wang, K.; Shen, L.; Song, C.; Zhang, Y.; Chen, P. The electrical performance and conductive network of reduced graphene oxide-coated ultra-high-molecular-weight polyethylene fibers through electrostatic interaction and covalent bonding. J. Appl. Polym. Sci. 2020, 137, 48946. [CrossRef]

35. Zhao, S.; Li, G.; Liu, H.; Dai, K.; Zheng, G.; Yan, X.; Liu, C.; Chen, J.; Shen, C.; Guo, Z. Positive Temperature Coefficient (PTC) evolution of segregated structural conductive polypropylene nanocomposites with visually traceable carbon black conductive network. Adv. Mater. Interfaces 2017, 4, 201700265. [CrossRef]

36. Wang, R.; Zheng, Y.; Chen, L.; Chen, S.; Zhuo, D.; Wu, L. Fabrication of high mechanical performance UHMWPE nanocomposites with high-loading multiwalled carbon nanotubes. J. Appl. Polym. Sci. 2019, 137, 48667. [CrossRef]

37. Zhou, H.; Xiao, Z.; Wang, Y.; Hao, X.; Xie, Y.; Song, Y.; Wang, F.; Wang, Q. Conductive and fire-retardant wood/polyethylene composites based on a continuous honeycomb-like nanoscale carbon black network. Constr. Build. Mater. 2020, $233,117369$. [CrossRef]

38. Li, Y.; Huang, X.; Zeng, L.; Li, R.; Tian, H.; Fu, X.; Wang, Y.; Zhong, W.-H. A review of the electrical and mechanical properties of carbon nanofiller-reinforced polymer composites. J. Mater. Sci. 2018, 54, 1036-1076. [CrossRef]

39. Alam, F.; Choosri, M.; Gupta, T.K.; Varadarajan, K.M.; Choi, D.; Kumar, S. Electrical, mechanical and thermal properties of graphene nanoplatelets reinforced UHMWPE nanocomposites. Mater. Sci. Eng. B 2019, 241, 82-91. [CrossRef]

40. Li, S.; Huang, A.; Chen, Y.-J.; Li, D.; Turng, L.-S. Highly filled biochar/ultra-high molecular weight polyethylene/linear low density polyethylene composites for high-performance electromagnetic interference shielding. Compos. Part B Eng. 2018, 153, 277-284. [CrossRef]

41. Kadar, R.; Abbasi, M.; Figuli, R.; Rigdahl, M.; Wilhelm, M. Linear and nonlinear rheology combined with dielectric spectroscopy of hybrid polymer nanocomposites for semiconductive applications. Nanomaterials 2017, 7, 23. [CrossRef] [PubMed]

42. Ke, K.; Potschke, P.; Gao, S.; Voit, B. An ionic liquid as interface linker for tuning piezoresistive sensitivity and toughness in poly(vinylidene fluoride)/carbon nanotube composites. ACS Appl. Mater. Interfaces 2017, 9, 5437-5446. [CrossRef] [PubMed]

43. Xie, Y.; Tang, J.; Ye, F.; Liu, P. Microwave-assisted sintering to rapidly construct a segregated structure in low-melt-viscosity poly(lactic acid) for electromagnetic interference shielding. ACS Omega 2020, 5, 26116-26124. [CrossRef] [PubMed]

44. Song, Y.; Zheng, Q. Concepts and conflicts in nanoparticles reinforcement to polymers beyond hydrodynamics. Prog. Mater. Sci. 2016, 84, 1-58. [CrossRef]

45. Wang, S.; Huang, Y.; Zhao, C.; Chang, E.; Ameli, A.; Naguib, H.E.; Park, C.B. Theoretical modeling and experimental verification of percolation threshold with MWCNTs' rotation and translation around a growing bubble in conductive polymer composite foams. Compos. Sci. Technol. 2020, 199, 108345. [CrossRef]

46. Abbasi, H.; Antunes, M.; Velasco, J.I. Recent advances in carbon-based polymer nanocomposites for electromagnetic interference shielding. Prog. Mater. Sci. 2019, 103, 319-373. [CrossRef] 